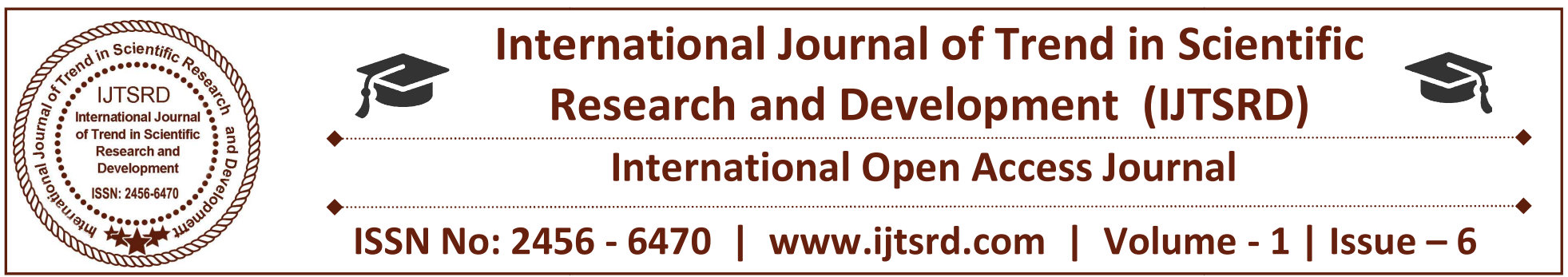

\title{
Application of IoT in Garbage Management System
}

\author{
Priti K. Gadge \\ Department of Electronics \& Telecommunication, \\ Government College of Engineering, \\ Chandrapur, Maharashtra, India
}

\author{
Dinesh V. Rojatkar \\ Department of Electronics \& Telecommunication \\ Government College of Engineering, \\ Chandrapur, Maharashtra, India
}

\section{ABSTRACT}

The term (IoT) Internet Of Thing was first invented in 1998.Kevin Ashton is father of IoT. IoT is derived from the two words -Internet and thing. We can simply say that transmission of anything over the Internet is IoT.

Many times in our city we see that garbage bins or dust bin which are placed at public places are overflowing with garbage. It is a universal truth that wastage of anything is harmful for society as well as to people and our environment is surrounded by natural things .It creates an unhygienic conditions as well as ugliness to that places which is may cause diseases. To solving this situations we are going to implement a project called IoT based smart garbage management system. This system monitors the garbage bins and informs about the level of garbage collected in the garbage bins through a web page and also sends all information to garbage collection van.

Keywords: Wi-Fi modem, microcontroller, Ultrasonic sensors, IoT, cloud server, Garbage management

\section{INTRODUCTION}

IOT: Internet and it's applications have become an integral part of today's human lifestyle .It has become an essential tool in every aspect. This paper gave us the details about mobile analysis and sensors information management that will help in data segregation of various dustbins. This is a very innovative idea which help us to keep our city clean.

Garbage Management System: In garbage management system garbage monitoring is needed.
Garbage Monitoring System - Garbage may consist of the unwanted material left over from city, public area, society, college, home etc. This project is related to the "Smart City" and based on "Internet of Things" .So for smart lifestyle, cleanliness is needed and cleanliness is begins with garbage bins.

This project will help to minimize the garbage disposal problem. The Internet of Things (IoT) is a recent communication paradigm that envisions near future, in which the objects of everyday life will be equipped with microcontrollers, transceivers for digital communication, and suitable protocol stacks that will make them able to communicate with one another and with the users. This project of IOT Garbage Monitoring system is a very innovative system which will help to keep the cities clean. This system monitors the garbage bins and informs about the level of garbage collected in the garbage bins via a web page. For this the system uses ultrasonic sensors placed over the bins to detect the garbage level and compare it with the garbage bins depth. The system makes use of Arduino family microcontroller, LCD screen. The LCD screen is used to display the status of the level of garbage collected in the bins. Whereas a web page is built to show the status of dust bins to the user for monitoring it. The web page gives a graphical view of the garbage bins and highlights the garbage collected in bins in color in order to show the level of garbage collected. The LCD screen shows the status of the garbage level. Thus this system helps to keep the city clean by informing about the garbage levels of the bins by providing graphical image of the bins via a web page. 


\section{LITERATURE SURVEY}

In solid waste bin monitoring system, garbage bin set at the public place then camera set at garbage bin location. In waste bin management system uses $\mathrm{Zig}$ bee and Global mobile communication system (GSM).The sensors are placed at the public place when garbage reaches the level of the sensors. Then that indicated will give in indication to the driver by sending SMS using GSM technology. This technique overcomes some disadvantages which are use of minimum route, low cost, fuel use, clean environment. For garbage detection weight sensor can be used .It gives the weight of the garbage in the dustbin. Smart garbage management system using ultrasonic sensor, microcontroller and GSM module. This system assures the cleanliness of dustbin soon when the garbage level reaches its maximum. Also smart bins can prevent the accumulation of the garbage along the roadside to a great extent thereby controlling the widespread of many diseases which can prevent pollution and prevent the consumption of the wastage of garbage by the street animals.

Hassan et.al is being proposed system in that novel prototype of solid waste bin monitoring system using wireless sensor network. He described that major challenges in urban areas throughout the world is management of solid waste. In that system he introduced an integrated system of solid combined of Radio Frequency Identification (RFID), Global Position System (GPS), General Packet Radio Services(GPRS), Geographic Information System (GIS), and Web Camera .The system is showed that real-time image processing and other bin information have been displayed in the GUI.

Kanchan Mahajan et.al described system, used two technologies. Zigbee and Global system for mobile communication (GSM) are the latest trends.

Pavithra et.al described a system id developed for to mainly, concentrate on eradicating not only ugliness but also disorder.

Yarlagadda Pravallika et.al described that today's scenario due to increase in population, increase in garbage. Proper garbage disposal is necessary to make environment clean, but improper garbage disposal, leads to various issues like health problems and thus affects the environment.

\section{PROPOSED DESIGN}

Our system is designed which is based upon online monitoring, ultrasonic sensors, cloud server and android mobile for hotspot. We use ultrasonic sensor to detect the level of the garbage. This sensor provides the ranges from very short to long range for detection. A cloud server is a logical server that is built hosted and delivered through a cloud computing platform over the internet. Depending upon the input condition the information is updated on cloud server using IOT as processed in SOC .Here the function of whole system is that as soon as the first garbage collecting van gets to $75 \%$.The main purpose of this project is to make aware the people from disposing their solid waste on the road or the nearby place. This will ultimately helps people or the surrounding from getting spoiled or polluted and daily on regular basis .This waste should be collected and disposed on the proper places. The microcontroller ESP8266 Wi-Fi module which is a self-contained system on a chip (SOC) which is based on IOT.SOC contained in built Wi-Fi. Android Mobile is used to fetch the GS data from cloud. User can get data via sms. GSM Modem is use for wireless communication. Application like data transmission GSM is used. GSM is low cost device and provide short message services. This a innovative project as we are using cloud server in it.

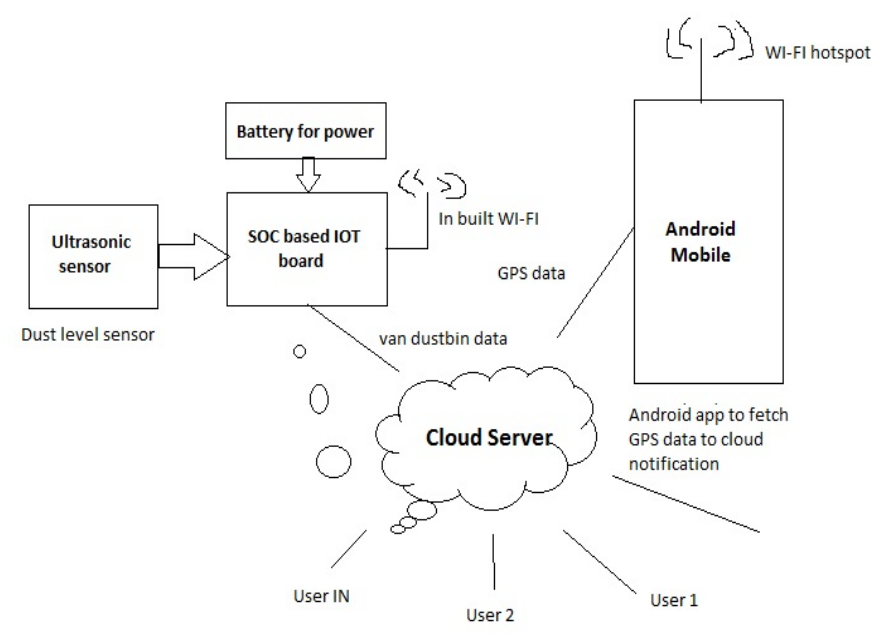

\section{Figure: Basis architecture of garbage management system}

\section{RESULT}

Garbage level, moisture level detection inside the garbage bin Transmission of information is wireless.

The real-time transmission of information carried out. Avoid the situation of overflowed dustbin. 


\section{FLOWCHART}

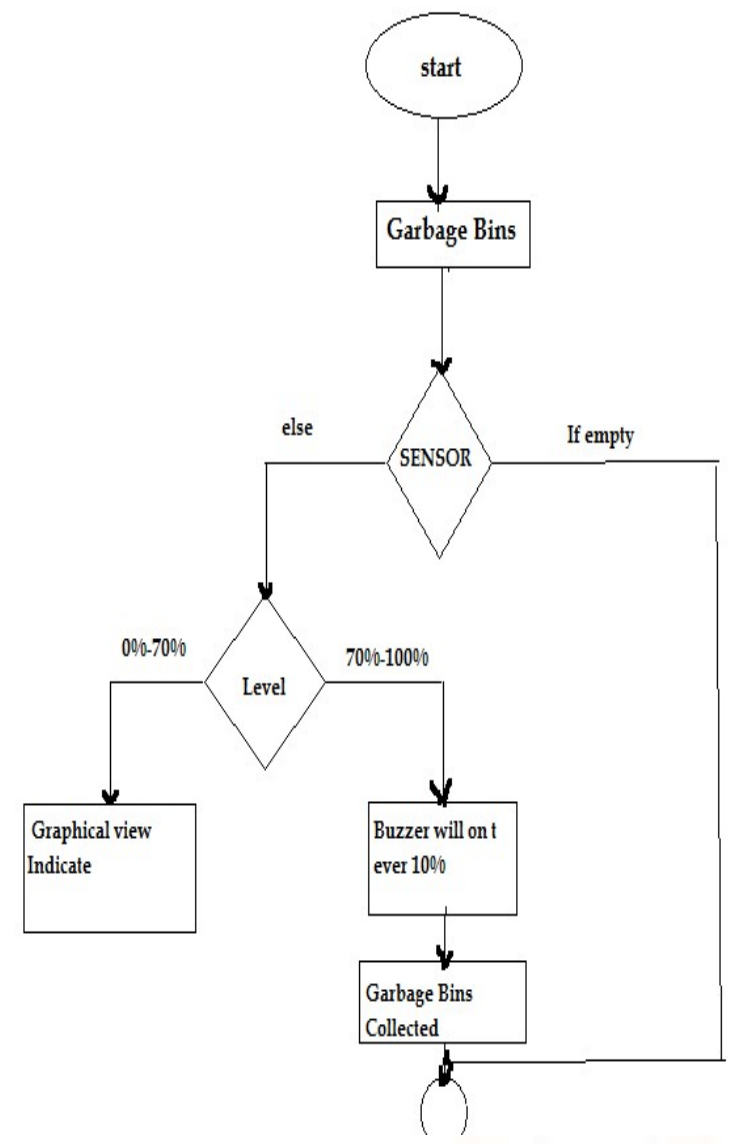

\section{ADVANTAGES}

Monitors the garbage bins, detect and informs about the level of garbage collected in the garbage or dust bins .

$>$ To keep our environment clean, hygienic and green

$>$ The low cost and efforts are less in this system

$>$ Ease of operation

$>$ Better quality of life.

$>$ Durability

$>$ Accuracy

\section{APPLICATIONS}

$>$ This project can be used in the "SMART CITY"

$>$ This project is helpful in the government project of "SWACHH BHARAT ABHIYAN"

$>$ Hotels

$>$ Domestic

\section{FUTURE SCOPE}

$>$ One of the main environmental benefits is reduced $\mathrm{CO} 2$ emission, which is a result of reduced waste vehicle traffic.
This trash van model can be applied to any smart cities around the world.

$>$ The combination of the IOT platform with other autonomous and intelligent system for providing smart and widespread applications is one of the most interesting future trends.

> The system can be implemented using stamp in which the real clock is full and when the truck driver has collected the waste.

\section{CONCLUSION}

This system also helps to monitor the fake reports and hence can reduce the corruption in the overall management system. This reduced the total number of trips of garbage collection vehicle or van and hence reduces the overall expenditure associated with the garbage collection .It ultimately helps to keep cleanliness in city. The technologies which are used in the proposed system are good enough to ensure the practical and perfect for solid garbage collection process monitoring and management for green environment. The objective of this project is for real time access of information about the dustbins. The novel cloud-based system for waste collection in smart cities. Hence in this project by making smart 
bins create awareness in people and make very responsible towards their society which ultimately help to become a smart city.

\section{REFERENCES}

1) Adil Bashir Concept, Design and Implementation of Automatic Waste Management System International Journal on Recent and Innovation Trends in Computing and Communication ISSN 23218169 Volume: 1 Issue: 7

2) Research Directions for the Internet of Things John A. Stankovic, Life Fellow, IEEE

3) Discussion Paper on the Internet of Things commissioned by the Institute for Internet and Society, Berlin Erin Anzelmo, Alex Bassi, Dan Caprio, Sean Dodson, Rob van Kranenburg, Matt Ratto October 2011.

4) IOT Based Green House Monitoring System Viswanath Naik.S Volume 6, Issue 6, June (2015), pp. 4547Article Id: 40120150606006 International Journal of Electronics and Communication Engineering Technology (IJECET)
5) Omoleke, I. I, (2004); Management of Environmental Pollution in Ibadan, An African City: The Challenges of Health Hazard Facing Government and The People, J. Hum.Ecol., 15(4):pp 265-275

6) Ajibade, L. T. et al. (2005): Quality Evaluation of Packed for Human Consumption in Ilorin, Kwara State: Proc. Nat. Conf., University of Ilorin.

7) Narayan Sharma Smart Bin Implementation for Smart Cities International Journal of Scienti_c Engineering Research, Volume 6, Issue 9, September-2015 ISSN 2229-5518

8) Kanchan Mahajan, Prof.J.S.Chitode "Waste Bin Monitoring System using Integrated Technology",'International Journal of Innovative Research in Science Engineering and Technology", vol 3, issue 7, july 2014.

9) Pavithra, "Smart Trash System: An applicating using Zigbee," International and Technology, vol. 1, issue 8 october 2014.

10) Md. Shafique Islam, M.A. Hannan, "An overview for Solid Waste Bin Monitoring System," Journal of Applied Science Research,8(2):879-886, February 2012. 